\title{
Benign gastrobronchial fistula with adenocarcinoma of the right mainstem bronchus
}

\author{
Simon Turcotte, MD, MSc, ${ }^{\mathrm{a}}$ Isabelle L. Cayer, MD, ${ }^{\mathrm{a}}$ Jean-Luc Laporte, MD, ${ }^{\mathrm{b}}$ Pasquale Ferraro, MD, ${ }^{\mathrm{a}}$ \\ Jocelyne Martin, MD, MSc, ${ }^{\mathrm{a}}$ and André Duranceau, MD, ${ }^{\mathrm{a}}$ Montreal, Quebec, Canada
}

Fistulization of the gastric conduit into the tracheobronchial tree is a potential complication after esophageal reconstruction. In this situation, the effects of the refluxate on the mucosa of the tracheobronchial tree is unknown. This article presents the 11-year evolution of a patient who tolerated a fistulous communication between the gastric interposition and the right mainstem bronchus, resulting in an adenocarcinoma of the bronchus.

\section{CLINICAL SUMMARY}

A 38-year-old man underwent an Ivor Lewis resection of a T3N1M0 distal esophageal adenocarcinoma. An esophagogastrostomy was completed above the azygos arch. All margins were negative. Metastasis was documented in 4 of 9 nodes. Within months of the operation, incapacitating reflux symptoms were present and controlled by antireflux medication. An asthma episode with a bout of hemoptysis prompted reinvestigation 1 year later. Esophagitis was found in the esophageal remnant without evidence of cancer or ulceration in the gastric reconstruction. Nonspecific changes were observed in the bronchial tree. Nineteen months after the esophagectomy, a new bronchoscopy documented a minute hole on the membranous wall of the right mainstem bronchus (Figure 1, $A$ ). Bronchial biopsies showed a squamous epithelium with gastric and incomplete intestinal metaplasia. A suspected gastrobronchial fistula could not be documented by contrast or endoscopic exploration. The patient denied aspiration symptoms and opted for upper gastrointestinal endoscopy surveillance without further bronchoscopic controls. Esophagitis and columnar-lined esophagus in the esophageal remnant were documented repeatedly on follow-up, but reflux symptoms were controlled by medication. Surgical treatment was offered but refused by the patient.

\footnotetext{
From the Department of Surgery and Division of Thoracic Surgery ${ }^{\mathrm{a}}$ and Department of Pathology, ${ }^{\mathrm{b}}$ Université de Montréal, Centre Hospitalier de l'Université de Montréal, Montreal, Quebec, Canada.

Disclosures: None.

Received for publication June 19, 2008; accepted for publication July 26, 2008; available ahead of print Feb 23, 2009.

Address for reprints: André Duranceau, MD, Department of Surgery, Université de Montréal, Division of Thoracic Surgery, Centre hospitalier de l'Université de Montréal, 1560 Sherbrooke E., Montreal, Quebec, Canada, H2L 4M1 (E-mail: andre. duranceau@umontreal.ca).

J Thorac Cardiovasc Surg 2010;139:e37-9 0022-5223/\$36.00

Copyright (c) 2010 Published by Elsevier Inc. on behalf of The American Association for Thoracic Surgery

doi:10.1016/j.jtcvs.2008.07.060
}

Eleven years after his esophagectomy, the patient presented respiratory difficulties. Bilateral basal pneumonia was diagnosed. At bronchoscopy, the initial pinhole orifice of the fistula on the membranous wall of the right bronchus had become a bulging mucosal lesion. Distal to this lesion, on the medial wall of the intermediate bronchus, a new irregular lesion was seen (Figure 1, B). Histology revealed a moderately differentiated adenocarcinoma (Figure 1,C). Investigation was negative for metastasis. Surgical treatment included resection of the right mainstem and intermediate bronchus in continuity with the posterior wall of the gastric conduit. The bronchial adenocarcinoma was superficial. Proximal and distal margins of the resected bronchi were negative. Subcarinal and peribronchial nodes were free of metastasis. The gastric interposition was defunctionalized, and a terminal parasternal esophagostomy was created. Via a laparotomy, the stomach was reduced in the abdomen and a gastrostomy was created. The middle and lower lobes were reimplanted at the carinal level, and the upper lobe was reinserted on the lateral wall of the trachea (Figure 2, $A$ and $B$ ).

The fistulous tract between the stomach and the bronchus was identified, lined with gastric metaplasia. In the bronchus, adjacent to the fistulous opening, foci of gastric metaplasia showed severe dysplasia. Bronchopulmonary infection cleared progressively, and gastrointestinal continuity was restored 5 months later. The former gastric conduit was mobilized and brought substernally to the neck. An antrectomy with duodenal diversion afforded a $60 \mathrm{~cm}$ Roux-en-Y reconstruction. After an uneventful recovery, the patient is asymptomatic.

\section{DISCUSSION}

Gastrobronchial fistula after esophagectomy and gastric interposition is rarely reported. Suggested causes include iatrogenic trauma on the membranous trachea ${ }^{1}$ or a perianastomotic complication. ${ }^{2}$ Without evidence of trauma or infection, terebrating ulcers of the gastric wall into the posterior wall of the bronchus remain possible. Post-esophagectomy prospective endoscopic follow-up reveals a $6.1 \%$ to $19.4 \%$ incidence of ulcer formation in the gastric reconstruction. ${ }^{3}$ Symptoms vary from mild to life threatening. Gastrointestinal contrast studies are more likely to establish the diagnosis than endoscopy. Small fistulas are more difficult to document. ${ }^{4}$ If a mixed type of refluxate from the gastric cavity finds its way into the tracheobronchial tree, the same mucosal complications as seen in reflux disease should 

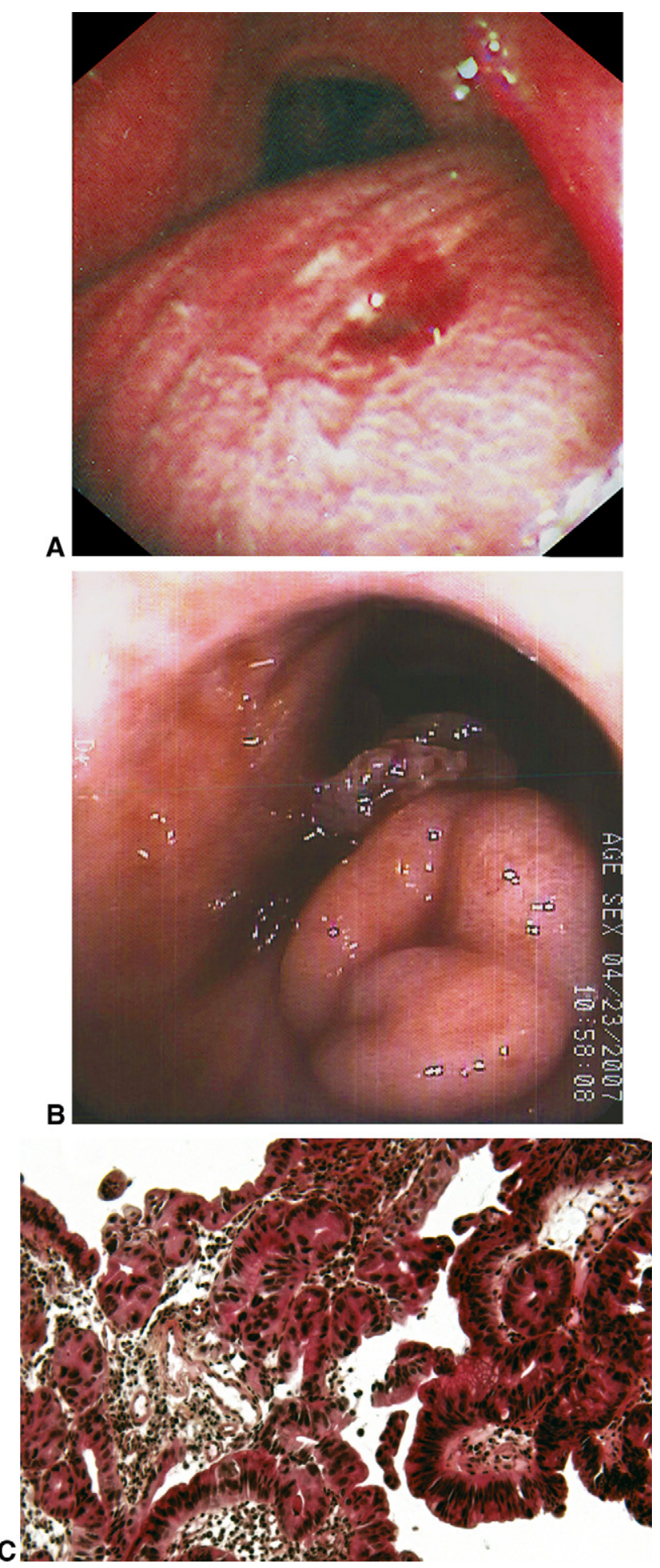

FIGURE 1. A, Minute hole on the membranous wall of the right main bronchus after biopsy. B, Endoscopic view 11 years after esophagectomy, the minute hole has become a soft bulging lesion. A second irregular lesion is found immediately distal on the medial wall of the intermediate bronchus. C, Hematoxylin-phloxine-saffron staining of the irregular lesion showing tubular and papillary fragments of moderately well-differentiated adenocarcinoma with invasion in the chorion.
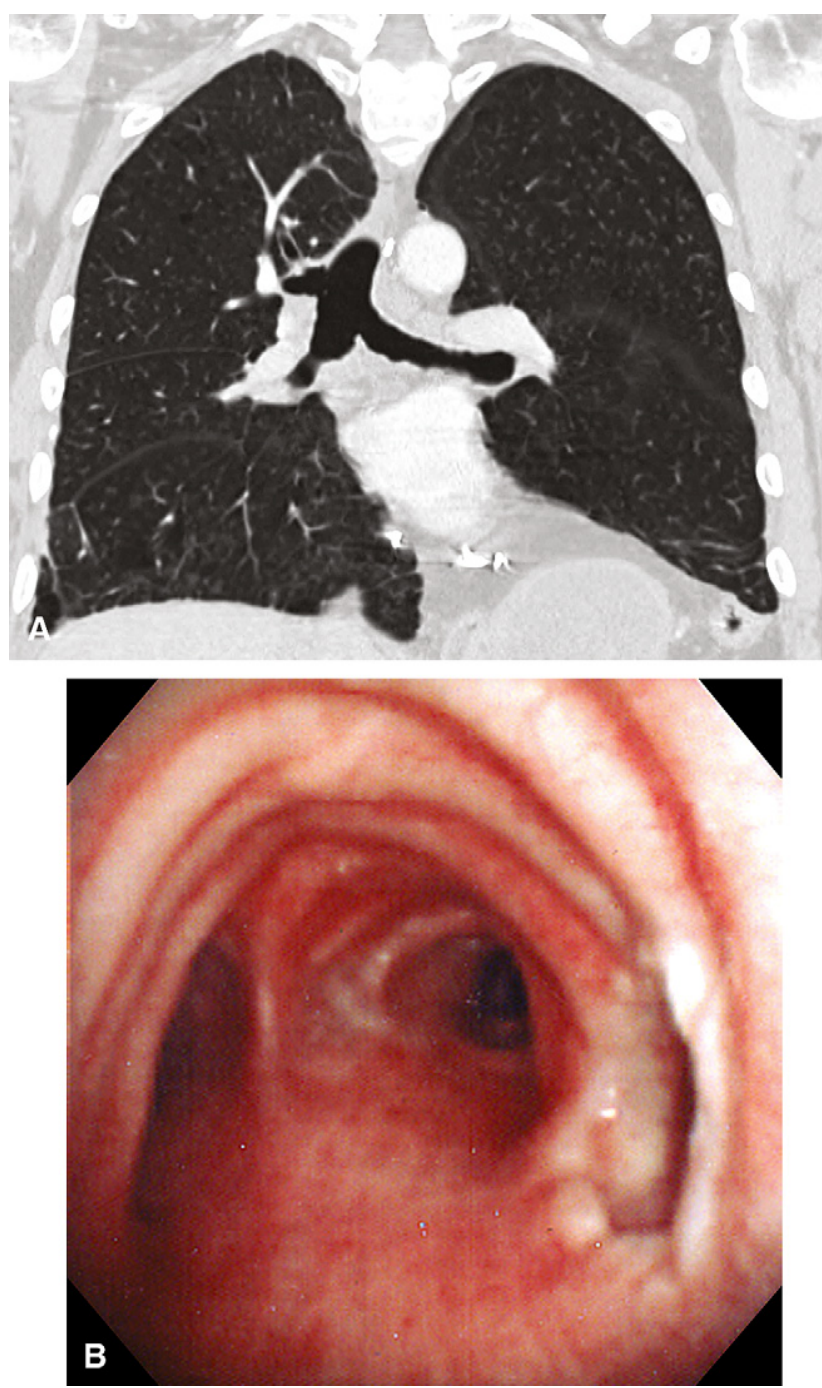

FIGURE 2. Middle and lower lobes reimplantation into the origin of the right mainstem bronchus. The upper lobe is anastomosed on the lateral wall of the trachea. A, Computed tomography scan, coronal view. B, Endoscopic view at 1 year.

be expected. Exclusion of the digestive tract from the tracheobronchial tree is needed first. Preservation of lung function, when possible, is essential. Staged reconstruction should favor progressive control of the lung infection and a return to normal pulmonary function. The use of covered stents cannot be seen as a definitive solution in a patient with no evidence of cancer recurrence. ${ }^{5}$

\section{CONCLUSIONS}

To our knowledge this is the first documented malignancy appearing in a bronchus at the outflow of a fistula bringing a mixed acid and pancreatobiliary refluxate in contact with the bronchial mucosa. In this nonsmoker, chronic inflammation of the airway by the reflux may well have provoked the cascade of transformation from inflammation to dysplasia 
and neoplasia. The inflammatory cell infiltrate present in the foci of the gastric metaplastic epithelium in lieu of the bronchial mucosa favors this hypothesis.

\section{References}

1. Marty-Ane CH, Prudhome M, Fabre JM, Domergue J, Balmes M, Mary H. Tracheoesophagogastric anastomosis fistula: a rare complication of esophagectomy. Ann Thorac Surg. 1995;60:690-3.
2. Hendren WG, Miller JI. Isolated, contained esophagobronchial fistula complicating esophagogastrectomy. Ann Thorac Surg. 1988;46:457-8.

3. Piessen G, Lamblin A, Triboulet JP, Mariette C. Peptic ulcer of the gastric tube after esophagectomy for cancer: clinical implications. Dis Esophagus. 2007;20:542-5.

4. Stal JM, Hanly PJ, Darling GE. Gastrobronchial fistula: an unusual complication of esophagectomy. Ann Thorac Surg. 1994;58:886-7.

5. Bona D, Sarli D, Saino G, Quarenghi M, Bonavina L. Successful conservative management of benign gastro-bronchial fistula after intrathoracic esophagogastrostomy. Ann Thorac Surg. 2007;84:1036-8.

\title{
Primary pulmonary meningioma: Ten-year follow-up findings for a multiple case, implying a benign biological nature
}

\author{
Yukitoshi Satoh ${ }^{\mathrm{a}, \mathrm{b}}$ and Yuichi Ishikawa, ${ }^{\mathrm{a}}$ Tokyo and Kanagawa, Japan
}

In 1998 we $^{1}$ reported the first case of multiple pulmonary meningioma, an extremely uncommon lung neoplasm. To date, there have been only 30 cases of primary pulmonary meningioma (PPM) reported in the English literature. $.^{1-3} \mathrm{Al}-$ though the lesions are widely known to be usually benign, slow growing, and to have an excellent prognosis, the etiology is still uncertain. Hence, several mechanisms have been proposed. ${ }^{1,3,4}$ We here report the clinical course of the initial case 10 years after surgery with examination by different imaging modalities and additional biopsy findings for a metachronous pulmonary lesion.

\section{CLINICAL SUMMARY}

A 74-year-old Japanese woman with a history of multiple PPM, undergoing surgery for lesions at the age of 64, was followed up by chest computed tomographic (CT) scan and magnetic resonance imaging (MRI) thereafter. During this period the patient was once referred to the Cancer Institute Hospital for percutaneous biopsy and cytologic examination of a new asymptomatic nodule that appeared in the right lower lung field 10 years after the first surgical resection (Figure 1). Histologic examination of the nodule revealed a benign PPM, which showed the same features as the lesion reported previously (Figure 2). Immunohistochemical staining performed by a standard avidin-biotin

\footnotetext{
From the Department of Pathology, ${ }^{\text {a }}$ Cancer Institute, Japanese Foundation for Cancer Research, Tokyo, and the Department of Thoracic Surgery, ${ }^{\mathrm{b}}$ Kitasato University School of Medicine, Kanagawa, Japan.

Disclosures: None.

Received for publication May 31, 2008; revisions received June 25, 2008; accepted for publication July 6, 2008; available ahead of print Dec 22, 2008.

Address for reprints: Yukitoshi Satoh, MD, Kitasato University School of Medicine, Department of Thoracic Surgery, 1-15-1 kitasato, Sagamihara-shi Kanagawa, 228-8555 Japan (E-mail: ysatoh@med.kitasato-u.ac.jp).

J Thorac Cardiovasc Surg 2010;139:e39-40

$0022-5223 / \$ 36.00$

Copyright (C) 2010 by The American Association for Thoracic Surgery

doi:10.1016/j.jtcvs.2008.07.059
}

immunoperoxidase technique demonstrated consistent expression of epithelial membrane antigen and vimentin in tumor cells. Conversely, results of studies for S-100 protein, AE1/AE3, CAM 5.2, muscle-specific actin (HHF-35), smooth muscle actin, synptophysin neuron-specific antigen, and desmin were negative. Furthermore, the tumor cells were focally positive for CD68 by KP-1 and progesterone receptor. Cytologic examination also demonstrated meningioma features, as for the lesion reported previously. ${ }^{1}$

MRI of the brain showed no abnormalities, and no intracranial or intraspinal masses were identified. On the basis of the morphologic features and the benign clinical course, the patient is being followed up by CT scan with informed consent. Although the right lung nodule has grown, the growth is very slow with a doubling time of 1011 days, the patient is asymptomatic, and there are no other new lesions in the lungs.

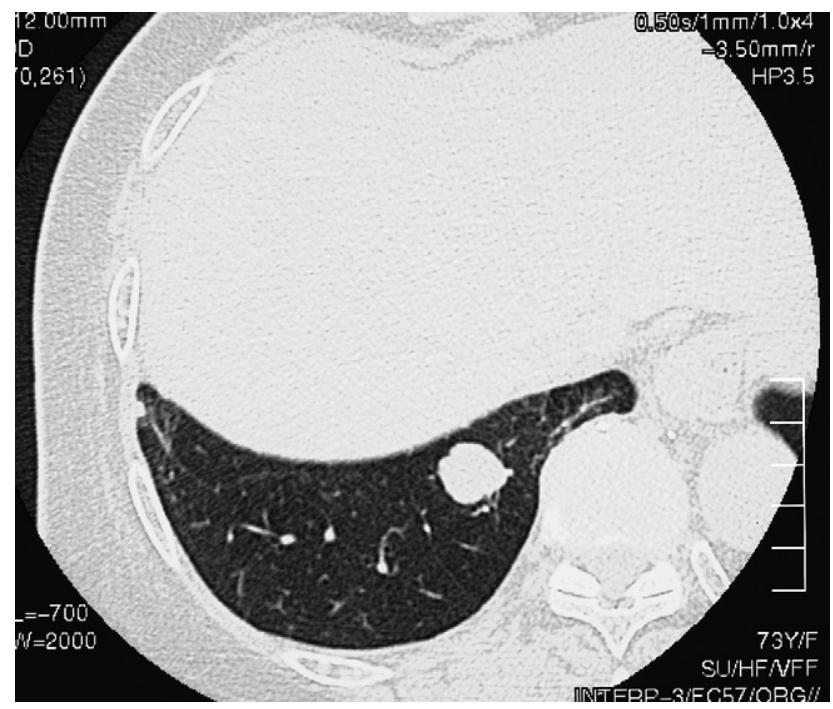

FIGURE 1. Chest computed tomographic scan showing a nodule in the right lower lung field. 